\title{
Hemolymphangioma of the waist: A case report and review of the literature
}

\author{
YONGCHAO LI ${ }^{1,2^{*}}$, XIAODONG PANG ${ }^{2 *}$, HONG YANG $^{2}$, CHUNHUA GAO $^{2}$ and BAOGAN PENG ${ }^{2}$ \\ ${ }^{1}$ Postgraduate Training Base, General Hospital of Armed Police Force, Liaoning Medical University, Jinzhou, \\ Liaoning 121000; ${ }^{2}$ Department of Spinal Surgery, Institute of Spinal Surgery of Armed Police Force, \\ General Hospital of Armed Police Force, Beijing 100039, P.R. China
}

Received June 26, 2014; Accepted February 26, 2015

DOI: $10.3892 / 01.2015 .3071$

\begin{abstract}
Hemolymphangioma is a malformation of the lymphatic and blood vessels. To the best of our knowledge, only a limited number of hemolymphangioma cases have been reported in the literature thus far, with no cases developed in the waist region. The present study reported the case of a 17-year-old male patient with hemolymphangioma growing on the waist, presented with back pain for four months. Upon physical examination, the lesion was identified to be oval in shape, soft and compressible, with mild tenderness. No abnormalities were detected in the results of laboratory examinations. However, a magnetic resonance imaging (MRI) scan revealed a tumor with low signal intensity on T1-weighted imaging (WI) and high signal intensity on T2-WI. The mass was successfully removed during surgery. During the seven-month follow-up period, the patient was asymptomatic with no evidence of recurrence. The present study discussed the imaging findings and pathological features of this uncommon case and reviewed the relevant literature.
\end{abstract}

\section{Introduction}

Lymphangioma, also known as angioma lymphaticum, is a congenital malformation of the vascular system, comprising newly-formed lymph spaces and channels (1). Landing and Farber (2) classified this benign malformation in four categories, including capillary, cavernous and cystic (hygroma) lymphangioma, and hemolymphangioma, which is a combination of hemangioma and lymphangioma.

Correspondence to: Professor Baogan Peng, Department of Spinal Surgery, Institute of Spinal Surgery of Armed Police Force, General Hospital of Armed Police Force, 69 Yongding Road, Beijing 100039, P.R. China

E-mail: pengbaogan76611@163.com

${ }^{*}$ Contributed equally

Key words: waist, hemolymphangioma, back pain
Hemolymphangioma is a congenital malformation that may be asymptomatic for a long period of time (3). This lesion is typically considered to be a benign and noninvasive disorder, characterized by the presence of dilated lymphatic spaces, extravasation of red blood cells, hemosiderin deposition and fibrosis (4). Hemolymphangioma formation may be due to venolymphatic communication obstruction between the dysembrioplastic vascular tissue and systemic circulation (5).

The incidence of hemolymphangioma is $1.2-2.8$ per 1,000 newborn infants (6). Hemolymphangioma has been previously detected at the pancreas (5,7-12), spleen (13-16), stomach $(1,17)$, rectum (18), mediastinum (19-21), chest wall (22-25), small intestine (26), extremities $(3,27,28)$, cervix $(29,30)$, pericardium (31), oral region (32), esophagus (33), axilla (34), retroperitoneal space $(35,36)$, adrenal gland (37), abdomen (38), duodenum (4) and hepatica (39), as well as on the tongue $(40,41)$ and orbit $(42,43)$. However, to the best of our knowledge, no studies have reported this type of tumor in the waist region, as determined by a review of the medical literature until June 2014 using the PubMed database (http://www.ncbi.nlm.nih.gov/pubmed; accessed on 9th June 2014). Complete excision is considered the optimal treatment for hemolymphangioma, which exhibits a low recurrence rate. Non-surgical treatments are also used, including aspiration and drainage, cryotherapy, injection of sclerotic agents, laser therapy and radiotherapy, however, to date, the outcomes of such treatments have been unsatisfactory $(3,22)$. In cases of tumor recurrence, conservative treatment methods such as laser therapy, may be applied $(3,44)$. Generally, the prognosis of hemolymphangioma is good $(3,4,13,17,18)$, however, careful follow-up is required.

The present study reported the case of a 17-year-old male patient with hemolymphangioma on the waist and reviewed the characteristics of this disease based on the existing literature.

\section{Case report}

A 17-year-old male was admitted at the General Hospital of Armed Police Force (Beijing, China) in September 2013, complaining of a mass on the right side of the waist and back pain for approximately four months. The back pain was significantly increased when the patient was sedentary and was slightly alleviated by rest. On admission, the patient was 

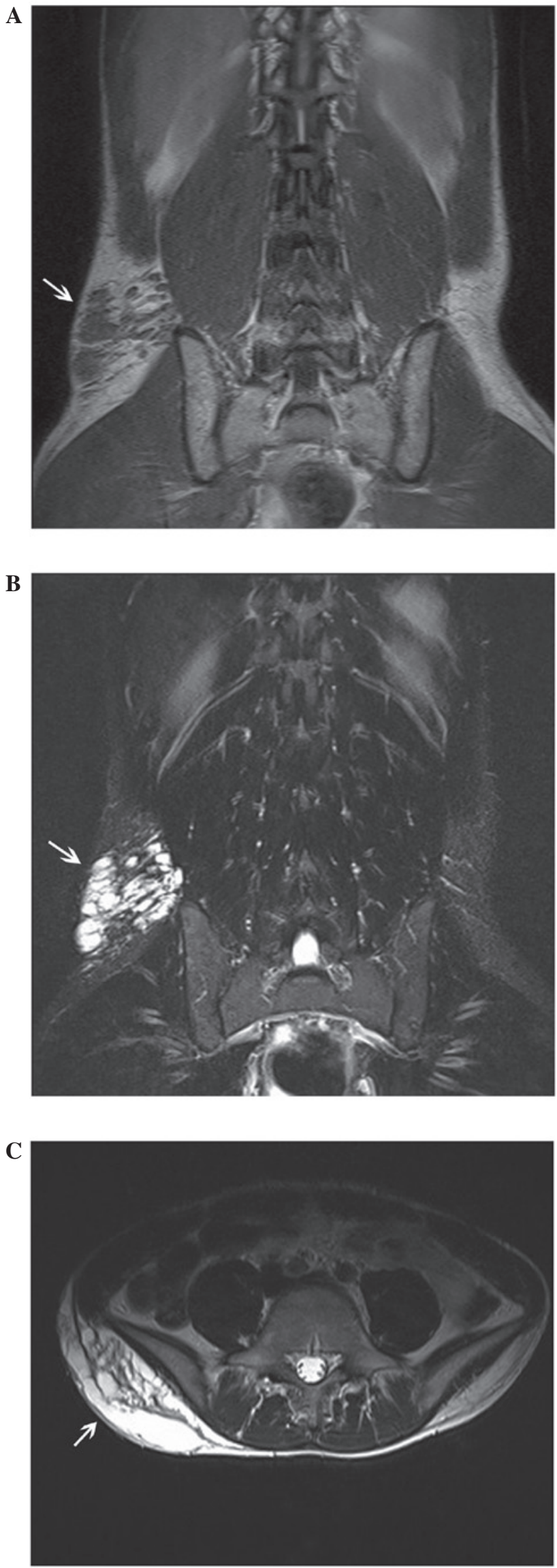

Figure 1. Magnetic resonance imaging (MRI) findings. The scans demonstrate the (A) coronal T1-weighted imaging (WI), (B) coronal T2-WI and (C) axial T2-WI. A mass (arrows) was identified, with low signal intensity on T1-WI and high signal intensity on T2-WI in the right side of the waist subcutaneous tissue with the fifth lumbar level parallel.

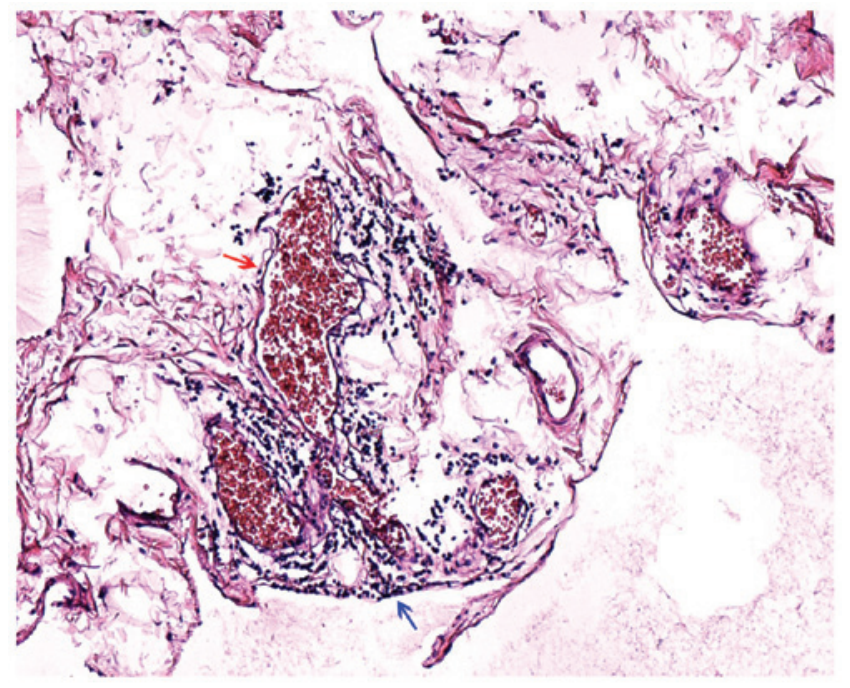

Figure 2. Histological analysis of biopsy specimen (hematoxylin and eosin stain; magnification, x100). Blood vessels (red arrow) and lymphatic vessels (blue arrow) can be observed in the tumor.

well, with no symptoms of lower extremity numbness and pain, or abdominal pain. Upon physical examination, the lesion was identified to be oval in shape, soft and compressible, with mild tenderness. No abnormalities were detected in the results of laboratory examinations. An ultrasound (Doppler sonography) detected a cystic lesion $(15.0 \times 10.0 \mathrm{~cm})$ with blood flow, and revealed multiple echo and irregular cavities in the subcutaneous fat layer of the right waist. The most likely diagnosis was hemolymphangioma.

Magnetic resonance imaging (MRI) examination was performed preoperatively, in order to establish the extent of the tumor and define its association with the surrounding tissues. A waist MRI scan (Fig. 1) revealed a 12.6x9.7-cm mass, with low signal intensity on T1-weighted imaging (WI) and high signal intensity on T2-WI in the right side of the waist subcutaneous tissue with the fifth lumbar level parallel. Upon performing a tumor biopsy with a 5-ml syringe, $10-\mathrm{ml}$ yellow, clear liquid was extracted and laboratory examinations were performed. Preoperatively, no abnormalities were revealed in the laboratory data, including the levels of tumor markers [ $\alpha$-fetoprotein, carcinoembryonic antigen, carbohydrate antigen (CA) 19-9, and CA-125] and concentrated mycobacterium tuberculosis.

Due to the patient experiencing back pain that was increased upon sitting, surgical excision was decided as the treatment strategy. During surgery, the boundary of the mass was unclear and a bloody yellow exudate was observed. Macroscopically, the mass measured approximately $12.0 \times 6.0 \times 6.0 \mathrm{~cm}$, and was oval and soft. Multiloculated cystic masses filled with blood and yellow fluid were extracted. Histologically, the tumor was composed of lymphatic and blood vessels with polycystic spaces (Fig. 2). Considering these observations, the definitive histological diagnosis was hemolymphangioma of the waist. The postoperative course of the patient was uneventful. In the course of a seven-month follow-up period, no recurrence of hemolymphangioma was observed. This study was approved by the ethics committee of General Hospital of Armed Police Force (Beijing, China) 
and written informed consent was obtained from the patient's family.

\section{Discussion}

Hemolymphangiomas, a congenital malformation of the vascular system, can be classified into primary and secondary lymphatic vascular tumors. Primary tumors are congenital malformations of the lymphatic vascular system, possibly formed due to obstruction of the venolymphatic communication between the dysembryoplastic vascular tissue and the systemic circulation. By contrast, secondary tumors are likely to be caused by poor lymph drainage and lymphatic damage resulting from surgery or trauma (43). Hemolymphangioma mainly presents as cystic or cavernous lesions. Histologically, hemolymphangioma is composed of dense fibrous tissue that develops in bands between the numerous vascular spaces, invading the subcutaneous fat and involving the blood or lymphatic vessels (3).

The incidence of hemolymphangioma is $1.2-2.8$ per 1,000 newborns (45), and the two genders are equally affected. In the present study, a review of the literature up to June 2014 was performed using the PubMed database. The search strategy to identify all possible studies involved use of the word 'hemolymphangioma'. In total, 47 previous studies concerning this type of tumor were identified (1,3-42,44,46-50). However, to the best of our knowledge, no studies have reported hemolymphangioma of the waist. In the current case, the patient was a 17-year-old male, and the tumor occurred on the waist and appeared as a cystic lesion.

Clinically, the onset of hemolymphangioma can vary between a slow-growing cyst over a period of years and an aggressive enlarging tumor without invasive ability (3). The size of these tumors varies due to the different anatomical location and association with the neighboring tissues. In clinical examinations, they are usually described as soft and compressible masses, loculated in pattern. The most common complications are random or traumatic hemorrhage, rupture and infection (3). However, no abnormal laboratory findings were observed in the current patient, and the only symptom was back pain for four months.

In the present study, a waist MRI scan revealed a tumor with low signal intensity on T1-WI and high signal intensity on T2-WI on the right side of the waist subcutaneous tissue in the fifth lumbar level. These observations may indicate the presence of a lower number of tortuous blood vessels and water-based substance in the lesion, which was then confirmed during surgery. Imaging examinations, including ultrasound, computed tomography and MRI scans, are useful in order to confirm the diagnosis, identify the tumor nature, and observe its extension and association with the surrounding tissues, assisting the selection of the surgical strategy and follow-up treatment (51). However, a definitive diagnosis of the tumor in the present study was based on histological evidence.

Surgical resection appears to be the most effective treatment for hemolymphangioma. In order to prevent recurrence, thorough radical resection may be required during surgery. In the English literature, the reported recurrence rates were in the range of $10-27 \%$ upon complete removal of the lesions, while the recurrence rates were $50-100 \%$ in cases where the lesions were partially removed $(4,52)$. The extend of surgical resection depends mainly on the anatomical location and complexity of the tumor $(3,4,12,52)$.

In conclusion, hemolymphangioma of the waist is an uncommon vascular and lymphatic lesion, presenting mainly with back pain. Preoperative imaging examinations, including ultrasound and MRI, are important for a full evaluation of the tumor in order to confirm the diagnosis and plan the surgical strategy. Complete surgical resection is the most effective treatment with good prognosis.

\section{References}

1. Li QY, Xu Q, Fan SF and Zhang Y: Gastric haemolymphangioma: a literature review and report of one case. Br J Radiol 85: e31-e34, 2012.

2. Landing BH and Farber S: Tumors of the Cardiovascular System. In: Atlas of Tumor Pathology. Armed Forces Institute of Pathology, Washington DC, pp.124-138, 1956.

3. Kosmidis I, Vlachou M, Koutroufinis A and Filiopoulos K: Hemolymphangioma of the lower extremities in children: two case reports. J Orthop Surg Res 5: 56, 2010.

4. Antonino A, Gragnano E, Sangiuliano N, et al: A very rare case of duodenal hemolymphangioma presenting with iron deficiency anemia. Int J Surg Case Rep 5: 118-121, 2014.

5. Balderramo DC, Di Tada C, de Ditter AB and Mondino JC: Hemolymphangioma of the pancreas: case report and review of the literature. Pancreas 27: 197-199, 2003.

6. Filston HC: Hemangiomas: cystic hygromas and teratomas of the head and neck. Semin Pediatr Surg 3: 147-159, 1994.

7. Sun LF, Ye HL, Zhou QY, et al: A giant hemolymphangioma of the pancreas in a 20-year-old girl: a report of one case and review of the literature. World J Surg Oncol 7: 31, 2009

8. Toyoki Y, Hakamada K, Narumi S, et al: A case of invasive hemolymphangioma of the pancreas. World J Gastroenterol 14: 2932-2934, 2008.

9. Banchini E, Bonati L and Villani LG: A case of hemolymphangioma of the pancreas. Minerva Chir. 42: 807-813, 1987 (In Italian).

10. Montete P, Marmuse JP, Claude R and Charleux H: Hemolymphangioma of the pancreas. J Chir (Paris) 122: 659-663, 1985 (In French).

11. Couinaud C, Jouan, Prot, Chalut, Favre and Schneiter: A rare tumor of the head of the pancreas. Hemolymphangioma weighing 1,500 kg. Presse Med 75: 1955-1956, 1967 (In French).

12. Couinaud,Jouan,Prot, Chalut and Schneiter: Hemolymphangioma of the head of the pancreas. Mem Acad Chir (Paris) 92: 152-155, 1966 (In French).

13. Zhang Y, Chen XM, Sun DL and Yang C: Treatment of hemolymphangioma of the spleen by laparoscopic partial splenectomy: a case report. World J Surg Oncol 12: 60, 2014.

14. Dong F, Zheng Y, Wu JJ, et al: Hemolymphangioma: a rare differential diagnosis of cystic-solid or cystic tumors of the pancreas. World J Gastroenterol 19: 3520-3523, 2013.

15. Bethouart M, Houcke M, Proye C and Linquette M: Hepatosplenic hemolymphangioma. Lille Med 25: 288-290, 1980 (In French).

16. Scaltriti F and Manenti A: Hemolymphangioma of the lower pole of the spleen (migrated into the pelvis minor). Chir Ital 19: 543-554, 1967 (In Italian).

17. Kim WT, Lee SW and Lee JU: Bleeding gastric hemolymphangioma: endoscopic therapy is feasible. Dig Endosc 25: 553-554, 2013.

18. Chen G, Cui W, Ji XQ and Du JF: Diffuse hemolymphangioma of the rectum: a report of a rare case. World J Gastroenterol 19: 1494-1497, 2013

19. Zehani A, Ayadi-Kaddour A, Cherif J, Marghli A, et al: Cystic mediastinal hemolymphangioma. Tunis Med 90: 754-755, 2012 (In French).

20. Contamin C, Denis B, Mallion JM, et al: Heart hemolymphangioma. Apropos of a case. Coeur Med Interne 12: 671-678, 1973 (In French).

21. Bagolan P,Alati E and Fisicaro M: Some defects of development of the mediastinum; three cases: one cavernous hemolymphangioma and two cystic hygromas. Archivio Chir Torace 10: 559-573, 1953 (In Italian). 
22. Zhang X, Sheng X, Liu F, et al: Hemolymphangioma of the chest wall: A rare case report. Oncol Lett 3: 816-818, 2012.

23. Bosdure E, Mates M, Mely L, et al: Cystic intrathoracic hemolymphangioma: a rare differential diagnosis of acute bronchiolitis in an infant. Arch Pediatr 12: 168-172, 2005 (In French).

24. Zernov NG, Poliakov VE and Vorob'eva ML: Diseases of the lymphatic vessels in children lymphangioma, hemolymphangioma, lymphangitis. Feldsher Akush 51: 27-29, 1986 (In Russian).

25. Sztaba R and Vondrat W: Thoracic hemolymphangioma with chylothorax in a newborn infant. Ann Chir Infant 6: 21-26, 1965 (In French).

26. Fang YF, Qiu LF, Du Y, Jiang ZN and Gao M: Small intestinal hemolymphangioma with bleeding: a case report. World J Gastroenterol 18: 2145-2146, 2012.

27. Beninson J and Hurley JP: Hemolymphangioma in a neonate-a therapeutic problem-case history. Angiology 39: 1043-1047, 1988.

28. Cole DJ, Sood SC and Broomhead IW: Pulmonary embolism associated with hemolymphangioma of lower extremity. Plast Reconstr Surg 63: 265-268, 1979.

29. Gaillard de Collogny L and Delage J: Cervical hemolymphangioma in a young patient. J Fr Otorhinolaryngol Audiophonol Chir Maxillofac 30: 469-473, 1981 (In French).

30. Bortolozzi G and Santoni G: Hemolymphangioma of the uterine cervix associated with early carcinoma. Minerva Ginecol 26 722-729, 1974 (In Italian).

31. Nataf P, Martin de Lasalle E, Benomar M, Gandjbakhch I and Cabrol C: Pericardial hemolymphangioma. Apropos of a case. Arch Mal Coeur Vaiss 81: 1137-1140, 1988 (In French).

32. Ullik R: On a hemolymphangioma of the floor of the mouth. Wien Klin Wochenschr 71: 958-960, 1959 (In German).

33. Canavese F, Cortese MG, Proietti L, et al: Bulky-pedunculated hemolymphangioma of the esophagus: rare case in a two-years old girl. Eur J Pediatr Surg 6: 170-172, 1996.

34. Tsonchev P: Hemolymphangioma cavernosum axillae dextrae. Khirurgiia (Sofiia) 11: 869-870, 1958 (In Bulgarian).

35. Kanaitsuka T, Itani K, Shigeta H, et al: A case report of giant retroperitoneal hemolymphangioma. Nihon Naika Gakkai Zasshi 76: 1595-1603, 1987 (In Japanese).

36. Houdart R, Palau R, Auclair E, Costa JC and Potet F: Infected retroperitoneal hemolymphangioma in an adult with the Klippel-Trenaunay syndrome. Ultrasonic diagnosis. Presse Med 15: 216, 1986 (In French).

37. Gossot D, Decazes JM, Sarfati E and Dubost C: Cystic hemolymphangioma of the adrenal gland. J Chir (Paris) 124: 404-405, 1987 (In French).

38. Giacalone PL, Boulot P, Marty M, et al: Fetal hemangiolymphangioma: a case report. Fetal Diagn Ther 8: 338-340, 1993.

39. Daudet M: Reflections apropos of a case of hepatic hemolymphangioma of the infant. Operation recovery. Pediatrie 20 445-451, 1965 (In French).
40. Laufer J and Girsault M: Hemolymphangioma of the tongue treated with combination embolization-surgery. Apropos of a case. Rev Stomatol Chir Maxillofac 87: 184-187, 1986 (In French).

41. Bureau Y, Delaire J, Barriere H, Litoux P and Bureau B: Hemolymphangioma of the tongue. Results of surgical treatment. Bull Soc Fr Dermatol Syphiligr 73: 422-423, 1966 (In French).

42. Chanfi M: Hemolymphangioma of the orbit in a young girl: a clinical observation. J Fr Ophtalmol 27: 1047-1049, 2004 (In French).

43. Guillot M, Dufier JL, Pierre-Kahn A, Nihoul-Fekete C, Lenoir G and Haye C: Hemolymphangioma of the orbit in children. Arch Fr Pediatr 40: 401-403, 1983 (In French).

44. Wang LC, Krunic AL, Medenica MM, Soltani K and Busbey S Treatment of hemorrhagic lymphatic malformation of the tongue with a pulsed-dye laser. J Am Acad Dermatol 52: 1088-1090, 2005.

45. Lu YY and Zhan AL: Imaging diagnosis of CT and MRI on hemolymphangioma. Zhongguo CT He MRI Za Zhi 8: 51-53, 2010 (In Chinese)

46. Fan Z, Li Y, Yan K, et al: Application of contrast-enhanced ultrasound in the diagnosis of solid pancreatic lesions--a comparison of conventional ultrasound and contrast-enhanced CT. Eur J Radiol 82: 1385-1390, 2013.

47. Cophignon J, d'Hermies F and Civit T: Vascular tumors of the orbit. Neurochirurgie 56: 197-212, 2010 (In French).

48. Riquet M, Briere J, Le Pimpec-Barthes F, et al: Cystic lymphangioma of the neck and mediastinum: are there acquired forms? Report of 37 cases. Rev Mal Respir 16: 71-79, 1999 (In French).

49. Giron J, Conte J, Chicoisne MP, Mazères F, Berjaud J and Dahan M: Cervico-mediastinal cystic lymphangioma. Ann Radiol (Paris) 35: 217-221, 1992 (In French).

50. Fontaliran F, Guillois B and Colin A: Congenital atrioventricular block and maternal lupus erythematosus. Histologic discovery of tumor of the atrioventricular node. Arch Mal Coeur Vaiss 82: 609-613, 1989 (In French).

51. Kennedy TL, Whitaker M, Pellitteri P and Wood WE: Cystic hygroma/lymphangioma: a rational approach to management. Laryngoscope 111: 1929-1937, 2001

52. Hebra A, Brown MF, McGeehin KM and Ross AJ III: Mesenteric, omental and retroperitoneal cysts in children: a clinical study of 22 cases. South Med J 86: 173-176, 1993. 